\title{
Evaluation of Chitosan Membrane with or without Autologous Platelet Rich Plasma in the Treatment of Gingival Recession: Histological Study in dogs
}

\author{
Enas A. Elgendy ${ }^{*}$, Samia A. Darwish ${ }^{2}$, Samia N. Serag ${ }^{2}$ and Amal M. Aldeeb ${ }^{3}$ \\ ${ }^{* 1}$ Lecturer of Oral Medicine, Periodontology, Oral Diagnosis and Radiology Department, \\ Faculty of Dentistry, October 6 University \\ ${ }^{2}$ Prof. of Oral Medicine, Periodontology, Oral Diagnosis and Radiology Department, \\ Faculty of Dentistry, Tanta University \\ ${ }^{3}$ Prof. of Oral Pathology Department, Faculty of Dentistry, Tanta University
}

Received: 25-11-2013

Accepted: 30-12-2013

Published:01-03-2014

*Corresponding author: E. mail: enaselgendy2005@yahoo.co.uk

$\mathrm{T}:+2-0122-4832580$

\begin{abstract}
Coverage of roots exposed by gingival recession is one of the main objectives of periodontal reconstructive surgery. Connective tissue graft (CTG) is preferred for treating most mucogingival recession defects and could be considered the gold standard. Chitosan is known to be natural polymers and it is available, biodegradable, biocompatible, and non-toxic and has antimicrobial and anti-inflammatory effects. Platelet rich plasma (PRP) is an autologous source of platelet derived growth factor and transforming growth factor beta that play a role in periodontal regeneration. The present study was designed to evaluate and compare chitosan membrane with or without PRP versus CTG in the treatment of Miller Class I buccal gingival recession $\geq 4 \mathrm{~mm}$ in width in dogs histologically. Miller Class I buccal gingival recession defects were surgically created in upper and lower canine of dogs. After 4 weeks, the defects were randomly assigned to one of the three treatment modalities, connective tissue graft + coronally advanced flap, chitosan membrane + coronally advanced flap or chitosan membrane + autologous plateletrich plasma + coronally advanced flap. . The animals were sacrificed using an overdose of anesthesia for histological examinations according to the following order: Two dogs were sacrificed at one month postsurgically and two dogs were sacrificed at two month post-surgically. The blocks were processed routinely in a way to obtain a panoramic view of the recession area for histological examination. Histological evaluation of the CTG revealed connective tissue fibers which were parallel to the root surface, and no histological evidence of new cementum, bone or periodontal ligament. On the other hand, histological evaluation of the chitosan membrane or chitosan membrane with PRP revealed new cementum, new bone formation, dense well organized highly cellular periodontal ligament fibers oriented perpendicular to the tooth surface and no migration of junctional epithelium. While CTG is the "gold standard" for root coverage in teeth with gingival recession the histological results of the present study revealed that CTG repaired by connective tissue. In contrast, the CAF with chitosan membrane with or without PRP was found to have all tissues necessary for regeneration, new cementum, well organized periodontal ligament fibers and new bone formation.
\end{abstract}

Key Words: Gingival recession, Connective tissue graft, Chitosan, Platelet rich plasma

\section{Introduction}

Gingival recession is defined as the displacement of the marginal tissue apical to the cementoenamel junction. Histologically, the destruction of gingival tissues, due to mechanical forces or inflammatory periodontal disease, is associated with loss of periodontal connective tissue fibers and alveolar bone. As a consequence, exposure of the root surface to oral environment will occur (1). Gingival recession and root exposure have presented a therapeutic challenge to clinicians for many years. Patients often complain about poor esthetics and root sensitivity. Later on, the longlasting recessions will be complicated by root 
caries and erosion. With an increased awareness of esthetics by both patients and dentists, various surgical procedures have been designed to correct gingival deformities esthetically as well as functionally. The main indications for root coverage procedures include esthetic demands, root sensitivity, and shallow carious lesions (2). Many techniques have been introduced to treat gingival recession, including autogenous free connective tissue grafts (CTG), coronally positioned flaps, orthodontics, pedicle grafts, free gingival grafts and guided tissue regeneration (GTR) (3).Coronally advanced flap (CAF) is one of the most effective treatments of Miller Class I and II recession defects. The mean percentage of root coverage obtained with this technique ranges from $55 \%$ to $99 \%$ (4-7). CAF may lead to excellent esthetics results, avoiding the need for a second surgical site; moreover, it is simple to perform and can be used to treat multiple recessions (8). CAF is sometimes problematic on account of the fragility of the gingival tissues and/or lack of attached gingiva. The subepithelial connective tissue graft (CTG), traditionally harvested from the patient's palate, is commonly used for root coverage in periodontal recession defects (9). The CTG obtains a closer color blend and keloid appearance is avoided compared to free gingival graft (FGG)(10). The different studies in the literature have confirmed the good results of this technique and subsequently it is considered as a gold standard therapy for patients with gingival recession. $(11,12)$ A limiting factor of this technique is the requirement of a remote surgical site to harvest the connective tissue. Often the donor site has more morbidity than the graft site and is associated with surgical challenges for the clinician. In addition, the amount of donor tissue is limited for any single surgical procedure (9). Guided tissue regeneration has become part of everyday surgical periodontal practice. These treatment modalities use barrier membranes which exclude fast growing cells (i.e., gingival epithelial, gingival fibroblasts) while enabling mesenchymal progenitor proliferation and differentiation into osteoblasts, periodontal ligament fibroblasts, and cementoblasts (13). These progenitor cells, given the space and enough time, are capable of restoring lost attachment around teeth (14). Nonabsorbable membranes have become less popular due to the need for a second surgery to retrieve them, and bioabsorbable membranes with comparable, if not better, clinical outcomes have become first choice in regenerative therapy. Commercially available bioabsorbable membranes are prepared from: dura-mater (15), polylactic acid, polyurethane (16), polyglycolic acid (17), and collagen. (14) Platelet-rich plasma (PRP) is an autologous source of platelet-derived growth factor (PDGF) and transforming growth factor (TGF) that is obtained by sequestering and concentrating platelets by gradient density centrifugation (18). PDGF is a family of polypeptide growth factors consisting of 2-chain polypeptides linked by disulfide bonds. PDGF is stored in the alpha granules of platelets and released during the clotting cascade PDGF acts as a potent mitogen in serum for mesenchymal cells, including fibroblasts and smooth muscle cells. TGF is a 2-chain polypeptide that is linked together by disulfide bonds TGF stimulates angiogenesis and the production of fibronectin, glycos-aminoglycans, and collagen in connective tissue. One of the most important functions of TGF seems to be the chemotaxis and mitogenesis of osteoblast precursors. In addition, this polypeptide inhibits osteoclast formation \& resorption and favoring bone formation (19). Natural products have served as a major source of drugs for centuries, and about half of the pharmaceuticals in use today are derived from natural products (20). Oriental medicines have been evaluated for their effects on periodontal disease, antibacterial and anti-inflammatory effects and periodontal tissue regeneration (21). Among these materials, chitosan (poly-N-acetyl glucose-minoglycan), is a derivative of chitin, which is the second most abundant natural biopolymer, and which is a primary structural component of the exoskeleton of arthropods such as crustaceans, the cell wall of fungi, and the cuticle of insects. Chitosan is obtained by Macetylating chitin, and it is a biodegradable natural biopolymer that is non-toxic and nonimmunogenic (22). The inductive and stimulatory activity of chitosan on connective tissue rebuilding was clearly demonstrated, and it was suggested that it could be considered a primer on which normal tissue architecture is organized. (23) In addition, studies have shown that chitosan has both antibacterial $(24,25)$ and anticandidal effects $(26,27)$. Due to the previously mentioned potentially beneficial properties of both chitosan and chitosan with PRP, the aim of this study was to compare the efficacy of these treatment modalities in sites with gingival recession. 


\section{Materials and Methods}

1- Chitosan (poly-N-acetyl glucosaminoglycan) membrane was prepared in the Faculty of Pharmacy, Phytochemistry Department follows: Chitosan powder was purchased from Sigma ${ }^{\circledR}$ (P.O. Box 14508. ST. LOUIS, MO 63103 USA) and the solution was prepared by dissolving 10 $\mathrm{mg}$ of chitosan powder in $2 \mathrm{ml}$ acetic acid. Thereafter, seven grams of methyl cellulose powder were dissolved in $100 \mathrm{ml}$ of boiled water to make the methyl cellulose gel. Chitosan solution was then mixed into the methyl cellulose gel to make the chitosan gel that was sterilized in the autoclave at $110^{\circ} \mathrm{c}$ for 20 minutes. In addition a glass slab $(20 \mathrm{~cm}$ x $20 \mathrm{~cm})$ was also sterilized in the autoclave with the chitosan gel. The sterile chitosan gel and the sterile glass slab were put in the ultraviolet incubator and the gel was spread on the glass slab and it was kept in the ultraviolet incubator for 2 days until it dried and changed into the membrane form. This membrane sheet was cut into multiple pieces $(2 \mathrm{~cm} \times 2 \mathrm{~cm})$ and put in a sterile bag to be ready for use. The ultraviolet incubator provided a sterile environment to get a sterile membrane.

2- Autologous platelet-rich plasma was prepared according to (18) as follows: $10 \mathrm{ml}$ of venous blood was drawn from each patient, blood was collected into sterilized disposable glass tubes that contained $1 \mathrm{ml}$ acid citrate dextrose, which functioned as an anticoagulant. The blood-containing glass tubes were centrifuged at 5,600 rpm for 10 minutes, which lead to separation of whole blood into blood cells and plasma layer. The plasma layer and uppermost part of the cell layer were drawn and placed into sterilized tubes. The tubes were then recentrifuged at 2,400 rpm for 10 minutes. The second centrifigation precipitate PRP at the bottom and clear strawcolored serum at the top. The serum was removed by long needle and PRP layer was then placed in a sterile container to be ready for use. 3-Tetracycline hydrochloride solution (10 $\mathrm{mg} / \mathrm{ml}$ ) was prepared by adding $250 \mathrm{mg}$ tetracycline powder from capsules to $25 \mathrm{ml}$ distilled water at room temperature.

\section{The experimental study:}

\section{The animal Model: (28)}

A total of 4 adult male mongrel dogs weighing from 20-25 $\mathrm{kg}$ were selected from the Physiology Department, Faculty of Medicine, Tanta University. The surgical procedures were performed under general anesthesia with intravenous injection of sodium thiopental $(12 \mathrm{mg} / \mathrm{kg})$. A notch was placed at the gingival margin using a small round bur (N1). Miller Class I buccal gingival recessions defects were surgically created ( 3 defects in each dog) at the buccal surfaces of the canines: 2 vertical incisions were made from the gingival margin and extended $5 \mathrm{~mm}$ apically. These incisions were connected apically by a horizontal incision and coronally by an intrasulcular incision. The gingival tissue limited by the 2 incisions was removed using a periosteal elevator. The exposed bone was removed using low speed rotary burs with irrigation by sterile saline. An apical notch was placed at the end of defect using small round bur as a landmark for the histopathologic examination (N2). All experimental sites were allowed to accumulate plaque for a period of 4 weeks to create plaque infected gingival recession defects. After 4 weeks the defects were randomly assigned to one of the following treatments:

\section{- Surgical protocol for CAF with CTG: (Figure 1)}

Recipient Site Preparation: Two oblique incisions connected by an intrasulcular incision were created. A trapezoidal split thickness mucoperiosteal flap was raised to the mucogingival junction, after this point, a partial thickness flap was extended apically. The root surface was instrumented with curettes and the necrotic cementum layer was removed. The root surface was conditioned with a saturated tetracycline solution $(10 \mathrm{mg} / \mathrm{ml})$ for 4 minutes using the burnishing technique with cotton pellets and changed at 30 seconds intervals. Following conditioning, the root surface was rinsed with sterile saline for 1 minute. The size and dimension of the CTG was determined using a sterile aluminum foil.

Donor site preparation: The aluminum template was affixed to the buccal ridge opposite to the molar region and a deep horizontal incision was placed, and two short parallel vertical incisions are made at the end of the horizontal incision, creating the door. A partial thickness "trap door" flap was reflected and from underneath a connective tissue graft was harvested. The trap door was replaced and sutured.

Graft placement: The graft was shaped to fit the recipient site and sutured on either side to the gingiva by $0-5$ resorbable sutures. Gingival flaps were coronally advanced and positioned to completely cover the CTG. Releasing incisions and flaps were closed using simple interrupted sutures. 


\begin{abstract}
- Surgical protocol for CAF with chitosan membrane (Figure 2): Two oblique incisions connected by an intrasulcular incision were created. A full thickness trapezoidal mucoperiosteal flap was raised to the MGJ. After this point, a split thickness flap was extended apically, releasing the tension and favoring the coronal positioning of the flap. The root surface was instrumented with curettes and the necrotic cementum layer was removed. Following conditioning of the root surface (as described previously), the chitosan membrane was adapted to cover the defect and the flap was coronally advanced to cover the membrane and sutured using simple interrupted sutures.
\end{abstract}

- Surgical protocol for CAF with chitosan membrane + PRP: Ten $\mathrm{ml}$ of venous blood was drawn from each dog, blood was collected into sterilized disposable glass tubes that contained 1 $\mathrm{ml}$ acid citrate dextrose as an anticoagulant. PRP was obtained in the same way as described previously for humans. The defects were treated with the same procedure except that the membrane was embedded in PRP before adaptation to cover the defect.

\section{Postsurgical care:}

- After the operative procedures the dogs received Acupan i.m every 12 hours for pain control for 2 days.

- Intra-muscular administration of antibiotics, Tetracycline HCL (Terramycine retard $125 \mathrm{mg}$ i.m., every 12 hours) during the first 2 days postoperatively. Thereafter, a tetracycline HCL capsule $(250 \mathrm{mg}$ ) was mixed with the dog's food (three times per day) for 7 days.

- The postoperative plaque control was performed by irrigation with $0.12 \%$ chlorhexidine gluconate every day.

- The dogs were fed a soft diet throughout the study evaluation period to reduce the chance of mechanical interference with healing during food intake.

\section{Histopathologic Examination:}

The animals were sacrificed using an overdose of anesthesia for histological examinations according to the following order:

- Two dogs were sacrificed at one month postsurgically.

- Two dogs were sacrificed at two months postsurgically.

The jaws were dissected and the blocks containing the experimental specimens were obtained (canine segment). The blocks were fixed in $10 \%$ neutral formalin solution for one week. Blocks biopsy specimens were transferred to $10 \%$ EDTA solution containing $5 \%$ sodium sulfide until demineralization occurred. The decalcified specimens were washed in running water, dehydrated and embedded in paraffin wax (the paraffin wax melting point should not exceed more than $56^{\circ} \mathrm{c}$ to avoid the burning of the tissues) for 24 hours and then embedded in paraffin blocks. All formalin-fixed-paraffinembedded tissues were serially cut buccolingualy with a rotary microtome at $5 \mu \mathrm{m}$ thickness. The sections were then placed on glass slides and incubated overnight at $60^{\circ} \mathrm{C}$ after which they were rehydrated in xylene, rinsed in ethanol and then water. The slides were stained with basic hematoxylin stain and counterstained with eosin for contrast and evaluation. (29) The 2 notches described previously were used as reference points in the histological examination.
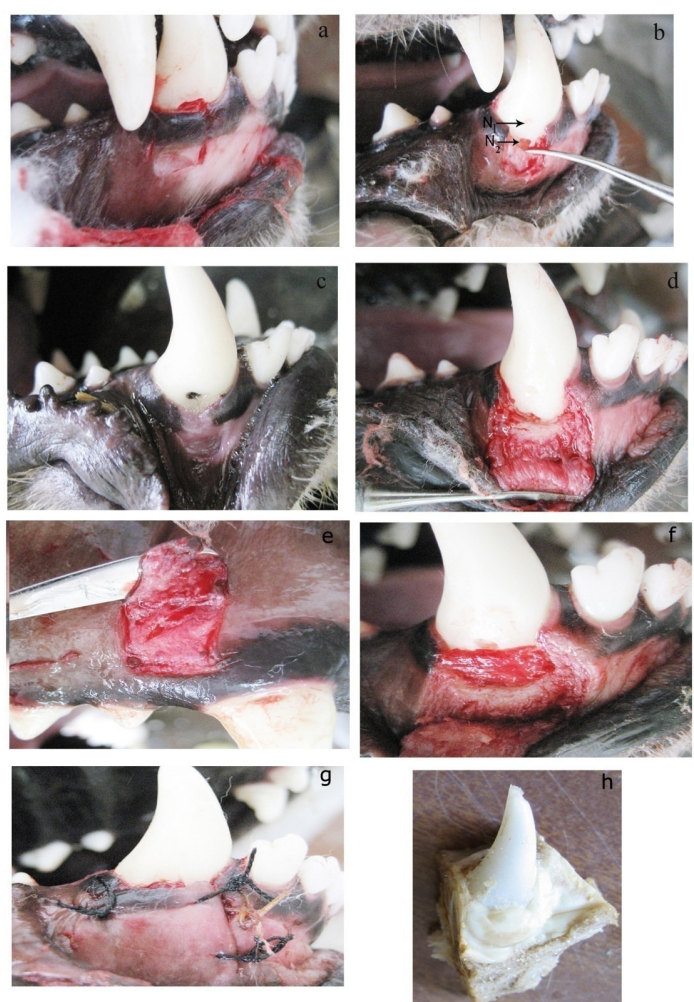

Figure 1: a, b, Soft and hard tissues removed, two notches one at the gingival margin preoperative position (N1) and another at the end of the created defect (N2), c, created gingival recession defect after 1 month of plaque accumulation, $d$, reflection of partial thickness flap, e, harvesting the CTG from keratinized mucosa, f, CTG placed over the defect, g, coronally advanced flap and suturing surgical sites, $\mathrm{h}$ the jaw was dissected and the canine segment was obtained. 

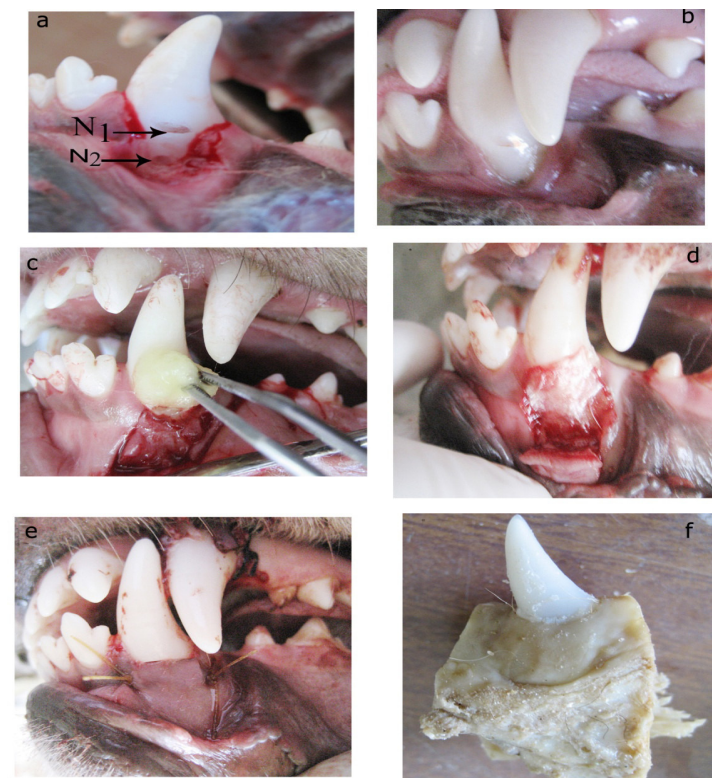

Figure 2: a, Soft and hard tissues removed, two notches one at the gingival margin preoperative position (N1) and another at the end of the created defect (N2), b, created gingival recession defect after 1 month of plaque accumulation, c, reflection of full thickness flap and conditioning of the root surface with tetracycline HCL, d, chitosan membrane in site, e, coronally advanced flap and suturing surgical sites, f, the jaw was dissected and the canine segment was obtained.

\section{Histological Results}

During the experimental period, all dogs remained healthy with normal behavior and consumption of food and water. No suppuration or abscess formation was observed at the site of the surgical procedures. The following are the results of the histological descriptive analysis for each treatment group.

Histological findings of the recession defects following surgery:

Group I (CTG + CAF).

One month post-surgery:

One month follows surgery, the histological findings revealed a long junctional epithelium ending apical to the notch at the original gingival margin (N1), bundles of non-inflamed connective tissue extended from the end of junctional epithelium to the notch at bone level (N2), evidence of a small amount of new cementum formation but no new bone formation. Overall, the analysis of the histological pictures reveals connective tissue fibers run parallel to the root surface between the tooth and the oral epithelium and no histological evidence of periodontal regeneration. Also, there was no evidence of any inflammatory cell infiltration interfering with healing (Figure 3).

\section{Two months post-surgery:}

The histological findings revealed junctional epithelium ending apical to the notch at the original gingival margin (N1). Bundles of noninflamed highly vascular organized connective tissue extended from the end of junctional epithelium to the notch at bone level (N2) parallel to tooth surface. Overall, the histological analysis of specimens revealed connective tissue coronal to the alveolar bone crest and no histological evidence of periodontal regeneration (Figure 4).
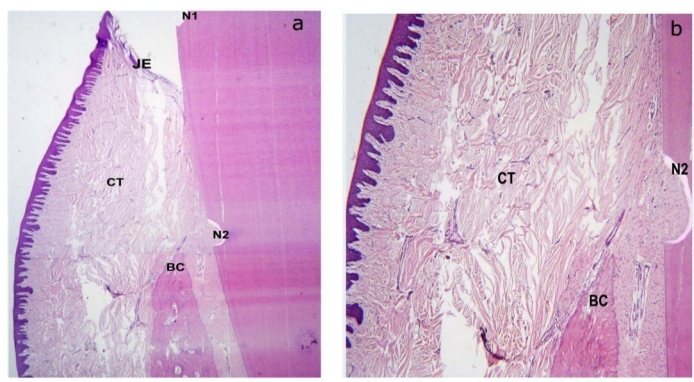

Figure 3: a, Labio-lingual section of CTG treated recession defect at one month post-surgery showing, the notch at the original gingival margin (N1) with the junction epithelium (JE) ending apical to the notch, non inflamed connective tissue (CT) run parallel to the root surface and bone crest (BC) ending at the apical notch (N2) (H\&E section, O.M.X10), b, Higher magnification of the previous section showing, no new bone formation, connective tissue run parallel to the root surface (H\&E section, O.M.X40),

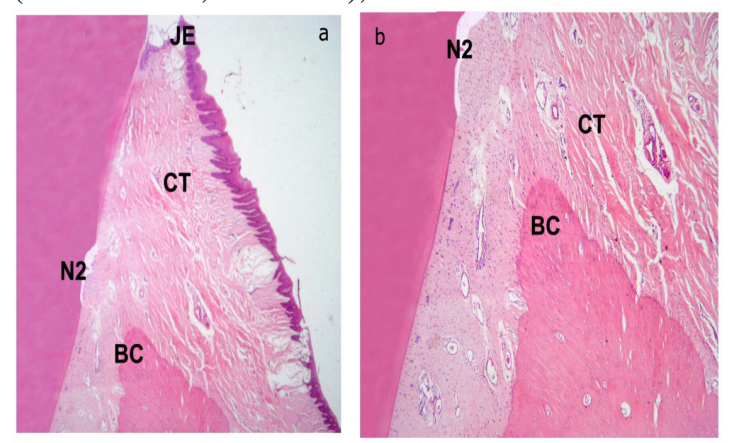

Figure 4: a, Labio-lingual section of CTG treated recession defect at two month post-surgery showing, the junction epithelium (JE), highly vascular organized connective tissue (CT), bone crest (BC) ending at the apical notch (N2) (H\&E section, O.M.X10), b, Higher magnification of the previous section showing, no new bone formation, highly vascular organized connective tissue (H\&E section, O.M.X40). 
One month post-surgery:

At one month, small bony specules coronal to the notch (N2) and newly formed bone in the apical part was observed. No migration of junction epithelium was observed. The new periodontal ligament, which was confined between new cementum and new alveolar bone, consisted of functionally oriented fibers perpendicular to the tooth surface and a large number of blood vessels. Area of acellular cementum was found to extend along the root (Figure 5).

Two months post-surgery:

H\&E stained section showed new attachment along the created recession defects and new bone coronal to $\mathrm{N} 2$. No migration of junction epithelium was observed. Dense well organized highly cellular periodontal ligament fibers perpendicular to the tooth surface was found to be inserted into the newly formed cementum and new bone coronal to notch (N2) and is delineated by reverse line (Figure 6).

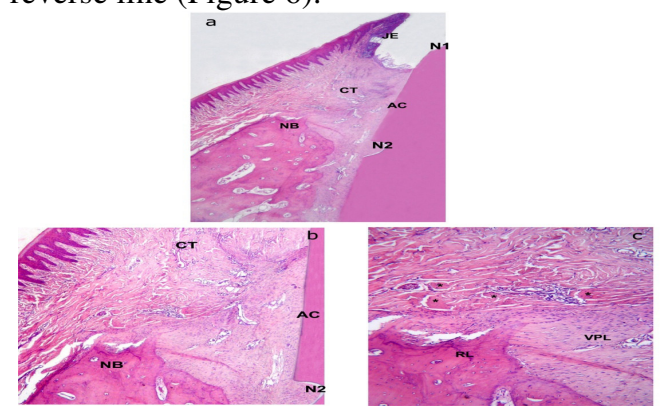

Figure 5: a, Labio-lingual section of CTG chitosan membrane treated recession defect at one month post-surgery showing, the notch at the original gingival margin (NI) with the junction epithelium (JE) ending at the notch,, highly vascular organized connective tissue (CT), layer of acellular cementum (AC) and new bone formation (NB) (H\&E section, O.M.X10),b, Higher magnification of the previous section showing, New bone (NB) formation coronal to the notch (N2)and highly vascular periodontal ligament fibers (VPL) (H\&E section, O.M.X40), c, Higher magnification of the previous section showing, New bone specules formation and function arranged vascular periodontal ligament fibers (VPL) (H\&E section, O.M.X100).

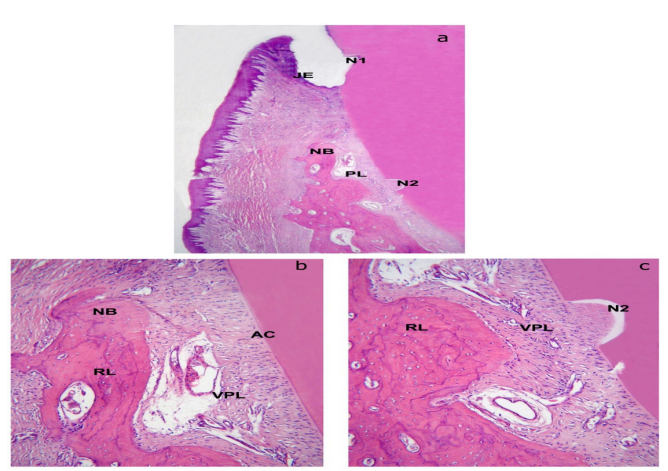

Figure 6: a, Labio-lingual section of CTG chitosan membrane treated recession defect at two month post-surgery showing, new bone formation (NB), well organized periodontal ligament (PL) and the junction epithelium (JE) ending at the notch, (H\&E section, O.M.X10),b,c Higher magnification of the previous section showing, New bone (NB) formation and highly vascular periodontal ligament fibers (VPL) (H\&E section, O.M.X100).

\section{Group III (chitosan membrane + platelet rich plasma + CAF): \\ One month post-surgery:}

At one month, the coronal part of the recession was filled with osteoid tissue and the apical part showed newly formed bone. No migration of junction epithelium was observed. The new periodontal ligament, which was confined between new cementum and new alveolar bone, contained fibroblasts, functionally oriented fibers perpendicular to the tooth surface and a large number of blood vessels. Areas of acellular cementum extended along the root were observed (Figure 7).

\section{Two months post-surgery:}

Coronal to the root notch (N2) complete healing of the periodontium that demonstrated similar features to native periodontium was observed.

Healing resulted in new attachment along the created recession defect, newly formed bone and osteoblastic cells were arranged along the bone marrow space. No migration of junctional epithelium was observed. Dense well organized highly cellular periodontal ligament fibers oriented perpendicular to the tooth surface was found to be inserted into the newly formed thick layer of cementum and bone (Figure 8). 


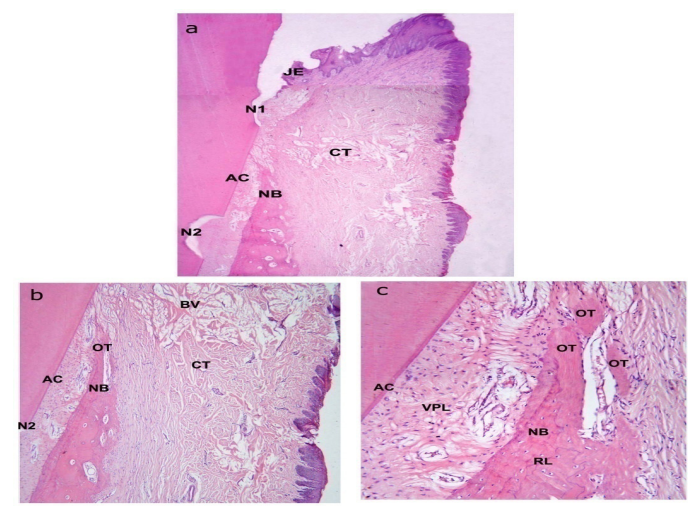

Figure 7: a, Labio-lingual section of CTG chitosan membrane +PRP treated recession defect at one month post-surgery showing, the notch at the original gingival margin (NI) with the junction epithelium (JE) ending at the notch,, highly vascular organized connective tissue (CT), layer of acellular cementum (AC) and new bone formation (NB) (H\&E section, O.M.X10),b, Higher magnification of the previous section showing, New bone (NB) formation coronal to the notch (N2), an area of osteoid tissue (OT) and highly vascular connective tissue (CT) (H\&E section, O.M.X40), c, Higher magnification of the previous section showing, vascular periodontal ligament fibers (VPL) perpendicular to the tooth surface, new bone (NB) with reversal lines and an area of osteoid tissue (OT)(H\&E section, O.M.X100).

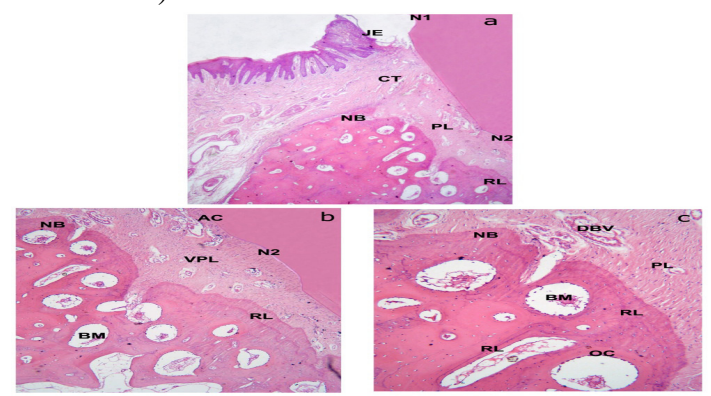

Figure 8: a, Labio-lingual section of CTG chitosan membrane +PRP treated recession defect at two month post-surgery showing, highly vascular organized connective tissue (CT), and new bone formation (NB) (H\&E section, O.M.X10),b, Higher magnification of the previous section showing, functional arranged vascular periodontal ligament fibers (VPL), New bone (NB) formation and acellular cementum (AC) (H\&E section, O.M.X40), c, Higher magnification of the previous section showing, vascular periodontal ligament fibers (VPL), dilated blood vessels (DBV), new bone (NB) with reversal lines and osteoblast cells lined the bone marow space (OC) (H\&E section, O.M.X100).

\section{Discussion}

The ultimate goal in periodontal therapy is regeneration. The establishment of a new connective tissue attachment with fibers inserting into new bone and new cementum on a previously diseased root surface is the ideal objective (30). In the current study healing of the recession defects was assessed after one and two months in dogs to evaluate and compare the regenerative response induced by the tested materials, chitosan and chitosan with PRP versus CTG. Several histological studies (31-33) reported that, an 8week healing interval was required to evaluate periodontal bone regeneration. Also Choi et al., (34) showed that, there was no significant difference in bone regeneration induced by bone morphogenic protein (BMP) between an 8 and 24weeks interval. Therefore, in our study, it was decided that an 8-weeks healing period is a sufficient period to observe the wound healing process. The placement of 2 reference notches was useful, where the gingival notch (N1) represented the exact location of the pre-operative gingival margin and the bone notch (N2) represented the end of the defect. Therefore, any connective tissue attachment observed in postsurgical examination coronal to $\mathrm{N} 2$ was considered new connective tissue attachment.

\section{Evaluation of histological results of the group I $($ CTG +CAF):}

At one month in group I, two different healing outcomes were demonstrated in current study. The first showed dense connective tissue fibers running parallel to the root surface, without new cementum or bone. No signs of root resorption or ankylosis were observed in any of the specimens. In the second dog treated with CTG, long junctional epithelium was observed on the coronal half of the defect, with no evidence of new bone or cementum formation. Loss of tight adaptation of the graft in the second dog in the early postsurgical period may have contributed to the failure of controlling epithelium migration, which was tightly adapted to the root surface in the first dog. While clinical findings in the current study and previous studies demonstrated that CTG is an effective method to obtain root coverage and represents the "gold standard" for root coverage technique (35), previous histological findings reported that this procedure did not produce true regeneration, only repair (35-37) which is in agreement with the results of the current study. At two months, overall, the histological analysis of specimens revealed bundles of non-inflamed connective tissue coronal to the alveolar bone 
crest and no histological evidence of periodontal regeneration. These results are in agreement with that reported by Majzoub et al., (37), who found that healing occurred after CTG via a long junctional epithelium throughout the major portion of the previous recession site after twelve months in an orthodontic patient who needed to extract of all 4 first premolars. Only minimal signs of new cementum-like tissue formation could be seen in the apical portion of the recession area coronal to the base of the instrumented root surface. No root resorption or ankylosis could be detected in any of the serial sections. Harris, (36) showed no evidence of regeneration in two recession defects treated with a CTG after 6 months in humans. There was long junctional epithelial attachment that extended well beyond the original gingival margin and occasionally almost to the original bone level with minimal connective tissue adjacent to the tooth. The other pattern was a short junctional epithelium that stopped at the previously exposed root surface. In this pattern, there was predominately connective tissue adjacent to the tooth with some isolated areas of epithelium. No new bone or cementum was seen in any section. In another report, Harris, (36) revealed areas of regeneration in CTG, with new bone, cementum, and connective tissue attachment coronal to the defect after 5 months post surgery in humans. The author postulated that defects with greater recession depth may have greater opportunity for regeneration. Goldstein et al., (38) reported regeneration of the attachment apparatus including new bone, cementum, and PDL following a root coverage procedure using CTG after 14 months post-surgery in humans. Bruno \& Bowers, (39) found that only the apical portion of the denuded root surface healed by regeneration (new bone, cementum, and PDL) and that the majority of the defects healed by connective tissue adhesion after 1 year in humans. The possible variations in the histological outcome of connective tissue grafts can be attributed to differences in size and shape of the recession defects and flap positioning at the end of surgery.

Evaluation of histological results of the group II (chitosan membrane + CAF) and group III (chitosan membrane + CAF+ PRP)

At one month of wound healing in group II and group III, histological analysis showed that the coronal part of the recession was filled with osteoid tissue and small bony specules. No migration of junctional epithelium was observed. The new periodontal ligament, which was confined between new cementum and new alveolar bone, contained fibroblasts, functionally oriented collagen fibers perpendicular to the tooth surface and a large number of blood vessels. Areas of acellular cementum extended along the root were observed.

New bone formation was demonstrated by Pang et al., (22) who concluded that chitosan $(0.1 \mathrm{mg} / \mathrm{ml})$ stimulated the expression of type I collagen mRNA and enhanced the alkaline phosphatase (ALPase) activity therefore enhanced the differentiation of human periodontal ligament fibroblast (hPDLF) into osteoblasts and accelerated new bone formation in rat calvarial critical size defects. Chitosan has structural characteristics similar to those of the glycosaminoglycans, specifically hyaluronic acid, and may mimic their functional behavior. Hyaluronic acid is thought to facilitate the migration and proliferation of progenitor cells, thereby facilitating tissue regeneration(40). The lack of junctional epithelial migration in the current study is in agreement with Park et al., (41), Yeo et al., (42), Shin et al., (43), Kuo et al., (44) and Hong et al., (45) who demonstrated that chitosan acts as a membrane and affected the regeneration of cementum, which inhibits epithelial migration, inducing the differentiation of undifferentiated mesenchymal cells into cementoblasts, as well as promoting the differentiation of osteogenic cells by an osteoconductive manner. In the present study, the functionally oriented collagen fibers were perpendicular to the tooth surface. Barney et al., (46) distinguished between two types of cementum regeneration. From the notch to the crest of new bone, the intrabony cementum showed an arrangement of cementoblasts. However, coronal to the crest, suprabony cementum with few cellular elements appeared to be a cementum-like substance with a parallel fiber adhesion. It was postulated that this suprabony cementum was of gingival origin, whereas the intrabony cementum with the perpendicularly inserted fibers was the true cementum that accompanied new attachment and healed by the fibers of periodontal ligament origin. At 2 months in the current study, in group II, dense well organized highly cellular periodontal ligament fibers perpendicular to the tooth surface was found to be inserted into the newly formed thin layer of cementum and new bone coronal to notch (N2) and was found to be delineated by reversal lines. In group III, newly formed bone and osteoblastic cells were arranged along the bone marrow space. No migration of junctional 
epithelium was observed in both groups. Complete healing of the periodontium that demonstrated similar features to native periodontium was observed. Platelet-derived growth factor (PDGF), transforming growth factors (TGF- $\beta 1$ ), Insulin-like growth factors (IGF-1), Fibroblast growth factors (FGF) and vascular endothelial growth Factor (VEGF) were reported in PRP. These growth factors stimulate and aid the proliferation of fibroblasts and periodontal ligament cells, as well as extracellular matrix formation, and promote collagen and total protein synthesis(47). In addition, they stimulate the synthesis of hyaluronate from gingival fibroblasts (48). PDGF-BB also demonstrated a significant stimulation of adherence of periodontal ligament cells to root surfaces while reducing the inhibitory effects of lipopolysaccharide on gingival fibroblast proliferation(49). TGF- $\beta 1$ is known to have an inhibitory effect on epithelial cell proliferation and $1 \mathrm{GF}-1$ is an important molecule that has strong effects on periodontal ligament fibroblast mitogenesis and protein synthesis in vitro. High levels of IGF-I are synthesized and secreted by osteoblasts, and, therefore, may regulate bone formation in an autocrine manner(50). FGF-b is chemotactic and mitogenic for periodontal ligament fibroblasts (51). In addition, VEGF was found to be critical for the formation of new blood capillaries in healing wounds and is important for the integrity of the endothelial lining of the vasculature. (52) Thus, collectively, PRP delivers significant amounts of growth factors, which are essential to wound healing and regeneration. It is known that cells in the periodontal ligament exhibit phenotypic characteristics consistent with osteoblast-like cells and have the potential to differentiate into osteoblasts and/or cementoblasts (53). It was suggested by Okuda et al., (54) that PRP modulates cell proliferation in a cell typespecific manner. PRP stimulated osteoblastic DNA synthesis and cell division with simultaneous down-regulation of alkaline phosphatase (ALP), but suppressed epithelial cell division. PRP also stimulated DNA synthesis in gingival fibroblasts and periodontal ligament cells. Its ability to suppress epithelial cell proliferation seems advantageous for periodontal regeneration by favoring the formation of a new connective tissue attachment on the root surface. In addition, PRP stimulates periodontal ligament cells and fibroblastic cell proliferation in vitro. Kawase et al., (55) demonstrated that PRP immediately induced fibrin clot formation and subsequently stimulated cellular adhesion and collagen synthesis. Type I collagen expression in periodontal ligament (PDL) cells was found to be stimulated through fibrin clot formation produced by the fibrinogen within PRP, rather than by the known growth factors. Cell adhesion and migration, modulated by growth factors, are essential for the healing process to progress. PRP may modulate several cell responses that have been involved in wound healing. It may stimulate adhesion to fibronectin, cell spreading, focal adhesion formation, fibroblasts migration and differentiation. Growth factors released after platelet activation and, in particular, PDGF isoforms were found to be able to stimulate chemotaxis of fibroblasts into the wounded tissue (56). Also growth factors present in PRP may stimulate myofibroblastic differentiation in gingival fibroblasts. Myofibroblastic differentiation constitutes an essential step in wound healing, and this cell phenotype is responsible for cell-mediated matrix contraction. Through contraction wound myofibroblasts are able to reduce the initial size of the wound and, thereby, contribute to tissue repair. These cells are also characterized by the expression of the actin isoform $\alpha$-sma which plays a significant role during granulation tissue contraction. TGF- $\beta 1$, a growth factor detected at high concentrations in PRP fractions, has been identified as an important inducer of the myofibroblastic phenol type (57).

The present study demonstrated that, healing in group III demonstrated similar histological features to native periodontium (more bone formation and cementum). This observation could be to chitosan which has the potential of releasing growth factors from PRP. This property makes it a possible substitute material for thrombin in PRP preparation, thereby avoiding the allergic and thrombotic effect of thrombin (58).

\section{References}

1. Trombelli L. Periodontal regeneration in gingival recession defects. Periodontol 2000. 19: 1999, 138-150.

2. Cueva MA, Boltchi FE, Hallmon WW, et al. A comparative study of coronally advanced flaps with and without the addition of enamel matrix derivative in the treatment of marginal tissue recession. J Periodontol. 75: 2004, 949-956.

3. Kassab MM and Cohen RE. Treatment of gingival recession. J Am Dent Assoc. 133: 2002, 1499-1506.

4. Allen EP and Miller PD. Coronal positioning of existing gingiva: short term results in the treatment of shallow marginal tissue recession. $J$ Periodontol. 60:1989, 316-319. 
5. Harris RJ and Harris AW. The coronally positioned pedicle graft with inlaid margins: A predictable method to obtain root coverage of shallow defects. Int J Periodontics Restorative Dent. 14: 1994, 229-241.

6. Trombelli L, Scabbia A, Wikesjö UM, et al. Fibrin glue application in conjunction with tetracycline root conditioning and coronally positioned flap procedure in the treatment of human gingival recession defects. $J$ Clin Periodontol. 23:1996, 861-867.

7. Pini Prato GP, Baldi C, Pagliaro G, et al. Coronally advanced flap procedure for root coverage. Treatment of root surface: Root planing versus polishing. J Periodontol. 70: 1999, 10641076.

8. Berlucchi I, Francetti L, Del Fabbro M, et al. The influence of anatomical features on the outcome of gingival recessions treated with coronally advanced flap and enamel matrix derivative: a 1-year prospective study. $J$ Periodontol. 76: 2005, 899-907.

9. Wilson TG Jr, McGuire MK and Nunn ME. Evaluation of the safety and efficacy of periodontal applications of a living tissueengineered human fibroblast-derived dermal substitute. II. Comparison to the subepithelial connective tissue graft: a randomized controlled feasibility study. J Periodontol. 76: 2005, 881889.

10. Cetiner D, Bodur A and Uraz A. Expanded mesh connective tissue graft for the treatment of multiple gingival recessions. J Periodontol. 75: 2004, 1167-72.

11. Clauser C, Nieri M, Franceschi D, et al. Evidence-based mucogingival therapy. Part 2: Ordinary and individual patient data metaanalyses of surgical treatment of recession using complete root coverage as the outcome variable. $J$ Periodontol. 74: 2003, 741-756.

12. Alkan A, Keskiner I and Yuzbasioglu E. Connective tissue grafting on resin ionomer in localized gingival recession. J Periodontol. 77: 2006, 1446-14451.

13. Nyman S, Gottlow J, Lindhe J, et al. New attachment formation by guided tissue regeneration. J Periodontal Res. 22: 1987, 252254.

14. Tal H, Pitaru S, Moses O, et al. Collagen gel and membrane in guided tissue regeneration in periodontal fenestration defects in dogs. J Clin Periodontol. 23: 1996, 1-6.

15. Garrett S, Loos B, Chamberlain D, et al. Treatment of intraosseous periodontal defects with a combined adjunctive therapy of citric acid conditioning, bone grafting, and placement of collagenous membranes. J Clin Periodontol. 15: 1988, 383-389.

16. Warrer K, Karring T, Nyman S, et al. Guided tissue regeneration using biodegradable membranes of polylactic acid or polyurethane. $J$ Clin Periodontol. 19:1992, 633-640.

17.Ziccardi VB and Buchbinder D. Guided tissue regeneration in dentistry. $N Y$ State Dent J. 62: 1996, 48-51.

18. Marx RE, Carlson ER, Eichstaedt RM, et al. Platelet-rich plasma: growth factor enhancement for bone grafts. Oral Surg Oral Med Oral Pathol Oral Radiol Endod 85:1998, 638-46.

19. Sanchez AR, Sheridan PJ and Kupp LI. Is platelet-rich plasma the perfect enhancement factor? A current review. Int J Oral Maxillofac Implants. 18: 2003, 93-103.

20. Clark AM. Natural products as a resource for new drugs. Pharm Res. 13: 1996, 1133-44.

21. Cao CF and Sun XP. Herbal medicine for periodontal diseases. Int Dent J. 48: 1998, 316-22. 22.Pang EK, Paik JW, Kim SK, et al. Effects of chitosan on human periodontal ligament fibroblasts in vitro and on bone formation in rat calvarial defects. J Periodontol. 76: 2005, 152633.

23. Muzzarelli R, Baldassarre V, Conti F, et al. Biological activity of chitosan: ultrastructural study. Biomaterials 9: 1988, 247-52.

24. Muzzarelli R, Tarsi R, Filippini O, et al. Antimicrobial properties of N-carboxybutyl chitosan. Antimicrob Agents Chemother. 34:1990, 2019-23.

25. Akncibay H, Senel S and Ay ZY. Application of chitosan gel in the treatment of chronic periodontitis. J Biomed Mater Res B Appl Biomater. 80: 2007, 290-296.

26.Roller $\mathrm{S}$ and Covill $\mathrm{N}$. The antifungal properties of chitosan in laboratory media and apple juice. Int J Food Microbiol. 1:1999, 67-77.

27. Aksungur P, Sungur A, Unal S, et al. Chitosan delivery systems for the treatment of oral mucositis: in vitro and in vivo studies. $J$ Control Release. 11: 2004, 269-79.

28. Gottlow J, Nyman S, Karring T, et al. Treatment of localized gingival recessions with coronally displaced flaps and citric acid. An experimental study in the dog. J Clin Periodontol. 13:1986, 57-63.

29. McGuire MK and Cochran DL. Evaluation of human recession defects treated with coronally advanced flaps and either enamel matrix derivative or connective tissue. Part 2: Histological evaluation. J Periodontol. 74:2003, 1126-35. 
30. Brunsvold MA and Mellonig JT. Bone grafts and periodontal regeneration. Periodontol 2000. 1: 1993, 80-91.

31.Polson AM and Caton J. Factors influencing periodontal repair and regeneration. $J$ Periodontol. 53: 1982, 617-625.

32. Sigurdsson TJ, Lee MB, Kubota K, et al. Periodontal repair in dogs: recombinant human bone morphogenetic protein-2 significantly enhances periodontal regeneration. J Periodontol. 66:1995, 131-8.

33. Kim CK, Cho KS, Choi SH, et al. Periodontal repair in dogs: effect of allogenic freeze-dried demineralized bone matrix implants on alveolar bone and cementum regeneration. J Periodontol. 69:1998, 26-33.

34. Choi SH, Kim CK, Cho KS, et al. Effect of recombinant human bone morphogenetic protein2/absorbable collagen sponge (rhBMP-2/ACS) on healing in 3 -wall intrabony defects in dogs. $J$ Periodontol. 73: 2002, 63-72.

35. Cortes Ade Q, Martins AG, Nociti FH Jr, et al. Coronally positioned flap with or without acellular dermal matrix graft in the treatment of Class I gingival recessions: a randomized controlled clinical study. J Periodontol. 75: 2004, 1137-44.

36. Harris RJ. Human histologic evaluation of root coverage obtained with a connective tissue with partial thickness double pedicle graft. A case report. J Periodontol. 70:1999, 813-21.

37. Majzoub Z, Landi L, Grusovin MG, et al. Histology of connective tissue graft. A case report. J Periodontol. 72:2001, 1607-15.

38. Goldstein M, Boyan BD, Cochran DL, et al. Human histology of new attachment after root coverage using subepithelial connective tissue graft. J Clin Periodontol. 28:2001, 657-62.

39. Bruno JF and Bowers GM. Histology of a human biopsy section following the placement of a subepithelial connective tissue graft. Int $J$ Periodontics Restorative Dent. 20:2000, 225-31.

40. Klokkevold PR, Vandemark L, Kenney EB, et al. Osteogenesis enhanced by chitosan (poly-Nacetyl glucosaminoglycan) in vitro. J Periodontol. 67:1996, 1170-1175

41.Park JS, Choi SH, Moon IS, et al. Eight-week histological analysis on the effect of chitosan on surgically created one-wall intrabony defects in beagle dogs. J Clin Periodontol. 30:2003, 443-53. 42. Yeo YJ, Jeon DW, Kim CS, et al. Effects of chitosan nonwoven membrane on periodontal healing of surgically created one-wall intrabony defects in beagle dogs. J Biomed Mater Res B Appl Biomater. 72: 2005, 86-93.
43. Shin SY, Park HN, Kim KH, et al. Biological evaluation of chitosan nanofiber membrane for guided bone regeneration. J Periodontol. 76:2005, 1778-1784.

44. Kuo SM, Chang SJ, Chen TW, et al. Guided tissue regeneration for using a chitosan membrane: an experimental study in rats. $J$ Biomed Mater Res A. 76:2006, 408-15

45.Hong H, Wei J and Liu C. Development of asymmetric gradational-changed porous chitosan membrane for guided periodontal tissue regeneration. Composites: Part B 38:2007, 311316.

46. Barney VC, Levin MP and Adams DF. Bioceramic implants in surgical periodontal defects. A comparison study. $J$ Periodontol. 57:1986, 764-70.

47. Matsuda N, Lin WL, Kumar NM, et al. Mitogenic, chemotactic, and synthetic responses of rat periodontal ligament fibroblastic cells to polypeptide growth factors in vitro. J Periodontol. 63:1992, 515-25.

48. Bartold PM. Platelet-derived growth factor stimulates hyaluronate but not proteoglycan synthesis by human gingival fibroblasts in vitro. $J$ Dent Res. 72:1993, 1473-80.

49. Bartold PM, Narayanan AS and Page RC. Platelet-derived growth factor reduces the inhibitory effects of lipopolysaccharide on gingival fibroblast proliferation. J Periodontal Res. 27:1992, 499-505.

50. McCarthy TL, Centrella $M$ and Canalis E. Regulatory effects of insulin-like growth factors I and II on bone collagen synthesis in rat calvarial cultures. Endocrinology 124:1989, 301-9.

51. Terranova VP, Odziemiec C, Tweden KS, et al. Repopulation of dentin surfaces by periodontal ligament cells and endothelial cells. Effect of basic fibroblast growth factor. J Periodontol. 60:1989, 293-301.

52. Geiger F, Bertram H, Berger I, et al. Vascular endothelial growth factor gene-activated matrix (VEGF165-GAM) enhances osteogenesis and angiogenesis in large segmental bone defects. $J$ Bone Miner Res. 20:2005, 2028-35.

53. Basdra EK and Komposch G. Osteoblast-like properties of human periodontal ligament cells: an in vitro analysis. Eur J Orthod. 19:1997, 615-21. 54. Okuda K, Kawase T, Momose $M$, et al. Platelet-rich plasma contains high levels of platelet-derived growth factor and transforming growth factor-beta and modulates the proliferation of periodontally related cells in vitro. $J$ Periodontol. 74:2003, 849-57.

55. Kawase T, Okuda K, Saito Y, et al. Plateletrich plasma provides nucleus for mineralization in 


\section{Elgendy, et al.,}

cultures of partially differentiated periodontal ligament cells. In Vitro Cell Dev Biol Anim. 41:2005, 171-6.

56. Seppä H, Grotendorst G, Seppä S, et al. Platelet-derived growth factor in chemotactic for fibroblasts. J Cell Biol. 92:1982, 584-8.

57. Cáceres M, Hidalgo R, Sanz A, et al. Effect of platelet-rich plasma on cell adhesion, cell migration, and myofibroblastic differentiation in human gingival fibroblasts. $J$ Periodontol. 79:2008, 714-20.

58. Shen EC, Chou TC, Gau CH, et al. Releasing growth factors from activated human platelets after chitosan stimulation: a possible bio-material for platelet-rich plasma preparation. Clin Oral Implants Res. 17:2006, 572-8. 